Pacific Journal of Mathematics

POLYNOMIALS IN CENTRAL ENDOMORPHISMS 


\section{POLYNOMIALS IN CENTRAL ENDOMORPHISMS}

\section{FraNkLiN HAIMO}

Let $\lambda$ be a central endomorphism of a group $G$ in the sense that $\lambda$ induces the identity map on the inner automorphism group of $G$. Despite the nearness of the situation to commutativity, it is not necessarily true that the central endomorphisms of $G$ form a ring or even that the subset generated by $\lambda$ be a ring. The displacement map $\tau$, given by $\tau(g)=$ $g^{-1} \lambda(g)$ for each $g \in G$, is an endomorphism with central values. We shall show (Theorem 1 ) that if $\tau$ satisfies a certain pair of simultaneous equations then $\lambda$ or $\lambda^{2}$ is idempotent. Let $P$ be a formal polynomial with integral coefficients, and let $t$ be the sum of these coefficients. Then (Theorem 2) $P(\lambda)$ is an endomorphism if and only if $t$ induces an integral endomorphism on $G$. If $G$ is nilpotent of class 2 then (Theorem 3 ) $P(\lambda)$ is an endomorphism if and only if $t(t-1) / 2$ is an exponent for the commutator subgroup $Q$ of $G$.

Theorem 3 gives us an alternate proof of an older (essentially equivalent) result [2, Th. 7, Corollary]. If $\alpha$ and $\beta$ are two maps in $G^{G}$, then $\gamma=\alpha+\beta$ is to mean the map given by $\gamma(g)=\alpha(g) \beta(g)$ for all $g \in G$. The symbol $c$ will be reserved for the identity map on $G$. By $\operatorname{diag}_{m} x$ we mean the $m$-by-m matrix with $x$ repeated down the main diagonal and with zeros elsewhere. If $1_{G}$ is the unity of the group $G$, we say that an integer $m$ is an exponent of $G$ if $g^{m}=1_{G}$ for each $g \in G$. An integer $m$ is said to induce an integral endomorphism on a group $G$ if $(x y)^{m}=x^{m} y^{m}$ for all $x, y \in G$.

1. Preliminaries. Let $\tau$ be a center-endomorphism of a group $G$. That is, $\tau$ is an endomorphism of $G$, and $\operatorname{Im} \tau \leqq Z$, the center of $G$. The map $\lambda \in G^{G}$ given by $\lambda(x)=x \tau(x)$ for each $x \in G$ is a normal endomorphism of $G$ in that it commutes with each inner automorphism of $G$. It is a central endomorphism in that $\lambda=\iota+\tau$ where $\tau$ is a center-endomorphism. See [3]. Each center-endomorphism of $G$ is likewise a normal endomorphism; but if $G$ is nonabelian, no such endomorphism is a central endomorphism. The central endomorphism $\lambda=\iota+\tau$ is said to be related to the center-endomorphism $\tau$. The set of all center-endomorphisms of a group $G$ is a ring $C(G)$ under endomorphism addition and composition.

If $\tau$ is a center-endomorphism of $G$ with related central endomorphism $\lambda$, then, with multiplication proceeding from left to right with increasing $i$ and with $C(n, i)$ as the usual binomial coefficient, we have 


$$
\lambda^{n}(x)=x \prod_{i=1}^{n} \tau^{i}\left(x^{C(n, i)}\right)
$$

and

$$
\tau^{n}(x)=\left[x \prod_{i=1}^{n} \lambda^{i}\left(x^{(-1) i_{C(n, i)}}\right)\right]^{(-1) n}
$$

for each $x \in G$ and for each positive integer $n$. From $\left(A_{n}\right)$, each $\lambda^{n}$ is a central endomorphism related to $\sum_{i=1}^{n} C(n, i) \tau^{i} \in C(G)$ where $\lambda$ is related to $\tau$. One readily sees that $\lambda$ is idempotent if and only if $-\tau$ is idempotent. Under this assumption, $\tau^{2 j+1}=\tau=-\tau^{2 j}$ for each positive integer $j$.

Observe that the $2^{n}$ factors on the right of $\left(B_{n}\right)$ can be rearranged at will. In fact, if one considers the mapping $P(\lambda)=\sum_{i=0}^{n} a_{i} \lambda^{i}$ where the $a_{i}$ are integers with $a_{n} \neq 0$, where $\lambda^{0}=\iota$, and where $P(\lambda) x=$ $\Pi_{i=0}^{n} \lambda^{i}\left(x^{a_{i}}\right)$ for each $x \in G$, then the terms of $P(\lambda)$ can be rearranged in any way. Nevertheless, $P(\lambda)$ need not be an endomorphism. If, however, it is an endomorphism, then it is normal. Call $n$ the degree of $P$.

THEOREM 1. Let $\tau$ be a center-endomorphism with related central endomorphism $\lambda$ on a group $G$.

(a) Suppose that there exist integers $m>0$ and $k \geqq 0$ such that $\tau^{2 m+k}+\tau^{m}=0$. Then there exists a formal polynomial $P$ with integral coefficients and of degree $2 m+2 k$ for which $\lambda$ is a zero.

(b) If there exists an integer $n \geqq 3$ such that $\tau+\tau^{n-1}=0=$ $\tau^{2}+\tau^{n-2}$, then $\lambda$ is idempotent if $n$ is odd; while if $n$ is even, $\operatorname{Im} \tau$ is elementary 2-abelian, $\lambda^{3}=\lambda^{2}$, and $\lambda^{2}$ is idempotent.

Proof. (a) From $\tau^{2 m+2 k}+\tau^{m+k}=0$ and the above remark on idempotents, the central endomorphism $\sigma$ related to $\tau^{m+k}$ must be idempotent. From $\left(B_{m+k}\right), \sigma$ must be of degree $m+k$ as a polynomial in $\lambda$. Let $T$ be the formal polynomial corresponding to $\sigma$. Let $P=$ $T^{2}-T$.

(b) $\tau=\tau^{3}$ so that $\tau^{2}=\tau^{4}$, all odd powers reducing to $\tau$, even to $\tau^{2}$. If $n$ is odd, then $\tau^{n-1}=\tau^{2}$ while $\tau^{n-2}=\tau$, from which $\tau^{2}=-\tau$ and $\lambda^{2}=\lambda$. If $n$ is even, $\tau^{n-1}=\tau$ whence $\tau^{n-1}+\tau=0$ yields $\tau\left(x^{2}\right)=1_{\theta}$ for every $x \in G$. At once, $\operatorname{Im} \tau$ is elementary 2-abelian. Now, $\left(A_{2}\right)$ leads to $\lambda^{2}(x)=x \tau^{2}(x)$ in this case. Applying $\lambda, \lambda^{3}(x)=x \tau\left(x^{2}\right) \tau^{2}(x)=\lambda^{2}(x)$. Thus, $\lambda^{3}=\lambda^{2}$, all higher powers reducing to $\lambda^{2}$. In particular, $\lambda^{2}$ is idempotent.

As an example of (b), take $G$ to be the group of $m$-by- $m$ nonsingular real matrices, and, for each matrix $A$ therein, let $\tau(A)=$ $\operatorname{diag}_{m}\left(|\operatorname{det} A|^{-1 / m}\right)$. It is clear that $\tau$ is a center-endomorphism of $G$ and that $\tau^{2}+\tau=0$. If we take $n=3$, we have the situation in (b). 
2. The sum of the coefficients. If $P$ is a polynomial with integral coefficients, let $t(P)$ denote the sum of these coefficients.

Lemma. Let $\alpha$ be a center-endomorphism of a group $G$, and let $\beta$ be a member of $G^{G}$. Then $\alpha+\beta$ is an endomorphism of $G$ if and only if $\beta$ is an endomorphism.

Proof. $(\alpha+\beta)(x y)=\alpha(x) \alpha(y) \beta(x y)$ while $(\alpha+\beta)(x)(\alpha+\beta)(y)=$ $\alpha(x) \beta(x) \alpha(y) \beta(y)$. Since $\alpha(y)$ is in the center, the result is clear.

If $k$ is an integer, let [k] be that member of $G^{G}$ which is given by $[k] x=x^{k}$ for each $x \in G$. Observe that if $\tau$ is a center-endomorphism of $G$, then $\tau$ generates a subring $\{\tau\}$ of $C(G)$.

THEOREM 2. Let $\tau$ be a center-endomorphism of a group $G$, and let $\lambda$ be its related central endomorphism. Let $P$ be a polynomial with integral coefficients.

(a) If $t(P)=0$, then $P(\lambda)$ is a center-endomorphism, a member of $\{\tau\}$.

(b) If $t(P)=1$, then $P(\lambda)$ is a central endomorphism related to some member of $\{\tau\}$.

(c) If $G$ is noncommutative and if $t(P)=2$, then $P(\lambda)$ is no endomorphism.

(d) If $t(P) \neq 0,1,2$, then $P(\lambda)$ is: (1) an endomorphism if and only, if $[t(P)]$ is an endomorphism on $G ;(2)$ a center-endomorphism if and only if $[t(P)]$ is a center-endomorphism on $G$; (3) a central endomorphism if and only if $[t(P)-1]$ is a center-endomorphism on $G$.

Proof. Suppose that $P(\lambda)=\sum_{i=0}^{n} a_{i} \lambda^{i}$ for integers $a_{i}$. Note that $\lambda^{0}=\iota$ and that, from $\left(A_{i}\right), \lambda^{i}=\iota+\sum_{j=1}^{i} C(i, j) \tau^{j}$ if $i>0$. Upon substitution, $P(\lambda)=\sum_{i=0}^{n} a_{i}\left(\iota+\sum_{j=1}^{i} C(i, j) \tau^{j}\right)=t(P) \iota+\sum_{i=1}^{n} q_{i} \tau^{i}$ for suitable integers $q_{i}$. (a) and (b) are now immediate. If $t(P)=2$, the lemma says that $2 \iota=[2]$ is an endomorphism of $G$ if and only if $P(\lambda)$ is an endomorphism. But [2] is an endomorphism if and only if $G$ is abelian, establishing (c). For $t(P) \neq 0,1,2$, the lemma gives (d), (1) and (2), directly. Now $P(\lambda)$ is central and related to a centerendomorphism if and only if $P(\lambda)=\iota+\sigma$ for some center-endomorphism $\sigma$. Equivalently, $(t(P)-1) \iota+\sum_{i=1}^{n} q_{i} \tau^{i}-\sigma=0$; that is, $(t(P)-1) \iota=$ $[t(P)-1]$ is a center-endomorphism on $G$, establishing (d), (3).

By (a) above, each $\lambda^{n}-\lambda$ is a center-endomorphism, $n=1,2, \cdots$. By (c), if $G$ is noncommutative, no $\lambda^{n}+\lambda$ is an endomorphism, $n=$ $1,2, \cdots$.

Recall that a group is (nilpotent) of class 2 if its inner automor. phism group is abelian. 
THEOREM 3. Let $G$ be a class 2 group, $\lambda$ a central endomorphism of $G$, and $P$ a polynomial with integral coefficients. Then $P(\lambda)$ is a normal endomorphism of $G$ if and only if $(t(P)-1) t(P) / 2$ is an exponent of $Q$.

Proof. Note that $P(\lambda)=\sum_{i=0}^{n} a_{i} \lambda^{i}$ is a normal endomorphism if and only if it is an endomorphism. Each $\lambda^{i}$ is central (by $A_{i}$ ). For $x, y \in G$, let $w$ denote $\left[y^{-1}, x^{-1}\right]=y^{-1} x^{-1} y x$. For a class 2 group, recall that $y^{b} x^{a}=x^{a} y^{b} w^{a b}$ and that $(x y)^{a}=x^{a} y^{a} w^{a(a-1) / 2}$ for all integers $a$ and $b$. By the centrality of the powers of $\lambda, \lambda^{i}\left(y^{b}\right) \lambda^{j}\left(x^{a}\right)=\lambda^{j}\left(x^{a}\right) \lambda^{i}\left(y^{b}\right) w^{a b}$ for all $x, y \in G$, all nonnegative integers $i$ and $j$, and all integers $a$ and $b$. It is now easy to show that $P(\lambda)(x y)=P(\lambda)(x) P(\lambda)(y) w^{E}$ where the integer $E=\sum_{i=0}^{n} a_{i}\left(a_{i}-1\right) / 2+\sum_{i<j} a_{i} a_{j}$. From a routine observation one sees that $E=(t(P)-1) t(P) / 2$.

Corollary. [2, Th. 7, Corollary] Let $s$ be an integer $\neq 0,1,2$. Let $G$ be a class 2 group for which $s(s-1) / 2$ is an exponent for $Q$. Then $[s]$ is an integral endomorphism for $Q$.

Proof. By the theorem, any polynomial $P$ with integral coefficients and with coefficient-sum $s$ has $P(\lambda)$ an endomorphism for each central endomorphism $\lambda$, and the set of all such $\lambda$ is nonempty. By Theorem 2 , (d), $[s]$ is an endomorphism on $G$.

As an example of this corollary, let $F$ be a commutative ring of finite characteristic and with a unity. Suppose that the characteristic $k=s(s-1) / 2$ for some integer $s>2$. Let $G$ be the set of all ordered triples $(a, b, c)$ over $F$ with multiplication given by $(a, b, c)\left(a^{\prime}, b^{\prime}, c^{\prime}\right)=$ $\left(a+a^{\prime}, b+b^{\prime}, c+c^{\prime}+b a^{\prime}\right)$. We have the well known class 2 group $G$ of triangular matrices

$$
\left(\begin{array}{lll}
1 & 0 & 0 \\
a & 1 & 0 \\
c & b & 1
\end{array}\right)
$$

where $Z=Q$ is the set of all $(0,0, x)$. Since $(0,0, x)^{n}=(0,0, n x)$, the characteristic $k$ is an exponent for $Q$. In general, $(a, b, c)^{n}=$ $(n a, n b, n c+(n(n-1) / 2) b c)$ for each integer $n$. An easy calculation now shows that $\left\{(\alpha, b, c)\left(a^{\prime}, b^{\prime}, c^{\prime}\right)\right\}^{s}-(a, b, c)^{s}\left(a^{\prime}, b^{\prime}, c^{\prime}\right)^{s}=\left(0,0,\left(s-s^{2}\right) b a^{\prime}\right)$. But $\left(s-s^{2}\right) b a^{\prime}=-2 k b a^{\prime}=0$, so that $[s]$ is indeed an integral endomorphism of $G$. 


\section{BIBLIOGRAPHY}

1. F. Haimo, Groups with a certain condition on conjugates, Canad. J. Math. 4 (1952), 369-372.

2. - Power-type endomorphisms of some class 2 groups, Pacific. J. Math. 5 (1955), 201-213.

3. W. Scott, Group Theory, Englewood Cliffs, New Jersey, 1964.

Received September 1, 1965. This research was supported jointly by the National Science Foundation and by Washington University under grants No. GP-89 and GP3874.

WASHINGTON UNIVERSITY 



\section{PACIFIC JOURNAL OF MATHEMATICS}

\section{H. ROYDEN}

Stanford University

Stanford, California

\author{
J. P. JANS \\ University of Washington \\ Seattle, Washington 98105
}

\section{EDITORS}

\author{
J. DugundJI \\ Department of Mathematics \\ Rice University \\ Houston, Texas 77001 \\ Richard ARENS \\ University of California \\ Los Angeles, California 90024
}

\section{ASSOCIATE EDITORS}
E. F. BECKENBACH
B. H. NeumanN
F. WOLF
K. YOSIDA

\section{SUPPORTING INSTITUTIONS}

\author{
UNIVERSITY OF BRITISH COLUMBIA \\ CALIFORNIA INSTITUTE OF TECHNOLOGY \\ UNIVERSITY OF CALIFORNIA \\ MONTANA STATE UNIVERSITY \\ UNIVERSITY OF NEVADA \\ NEW MEXICO STATE UNIVERSITY \\ OREGON STATE UNIVERSITY \\ UNIVERSITY OF OREGON \\ OSAKA UNIVERSITY \\ UNIVERSITY OF SOUTHERN CALIFORNIA
}

\author{
STANFORD UNIVERSITY \\ UNIVERSITY OF TOKYO \\ UNIVERSITY OF UTAH \\ WASHINGTON STATE UNIVERSITY \\ UNIVERSITY OF WASHINGTON \\ AMERICAN MATHEMATICAL SOCIETY \\ CHEVRON RESEARCH CORPORATION \\ TRW SYSTEMS \\ NAVAL ORDNANCE TEST STATION
}

Mathematical papers intended for publication in the Pacific Journal of Mathematics should be typewritten (double spaced). The first paragraph or two must be capable of being used separately as a synopsis of the entire paper. It should not contain references to the bibliography. Manuscripts may be sent to any one of the four editors. All other communications to the editors should be addressed to the managing editor, Richard Arens at the University of California, Los Angeles, California 90024.

50 reprints per author of each article are furnished free of charge; additional copies may be obtained at cost in multiples of 50 .

The Pacific Journal of Mathematics is published monthly. Effective with Volume 16 the price per volume (3 numbers) is $\$ 8.00$; single issues, $\$ 3.00$. Special price for current issues to individual faculty members of supporting institutions and to individual members of the American Mathematical Society: $\$ 4.00$ per volume; single issues $\$ 1.50$. Back numbers are available.

Subscriptions, orders for back numbers, and changes of address should be sent to Pacific Journal of Mathematics, 103 Highland Boulevard, Berkeley 8, California.

Printed at Kokusai Bunken Insatsusha (International Academic Printing Co., Ltd.), 7-17, Fujimi 2-chome, Chiyoda-ku, Tokyo, Japan.

PUBLISHED BY PACIFIC JOURNAL OF MATHEMATICS, A NON-PROFIT CORPORATION

The Supporting Institutions listed above contribute to the cost of publication of this Journal, but they are not owners or publishers and have no responsibility for its content or policies. 


\section{Pacific Journal of Mathematics}

A. A. Aucoin, Diophantine systems ............................. 419

Charles Ballantine, Products of positive definite matrices. I ............... 427

David Wilmot Barnette, A necessary condition for d-polyhedrality ............ 435

James Clark Beidleman and Tae Kun Seo, Generalized Frattini subgroups of finite groups ......................................... 441

Carlos Jorge Do Rego Borges, A study of multivalued functions ............. 451

William Edwin Clark, Algebras of global dimension one with a finite ideal

lattice ...............................................

Richard Brian Darst, On a theorem of Nikodym with applications to weak convergence and von Neumann algebras .........................

George Wesley Day, Superatomic Boolean algebras .....................

Lawrence Fearnley, Characterization of the continuous images of all

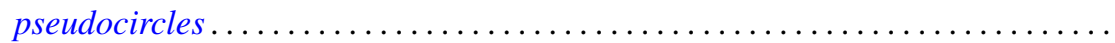

Neil Robert Gray, Unstable points in the hyperspace of connected subsets....... 515

Franklin Haimo, Polynomials in central endomorphisms .................. 521

John Sollion Hsia, Integral equivalence of vectors over local modular lattices . . . . 527

Jim Humphreys, Existence of Levi factors in certain algebraic groups .......... 543

E. Christopher Lance, Automorphisms of postliminal $C^{*}$-algebras ............ 547

Sibe Mardesic, Images of ordered compacta are locally peripherally metric . . . . 557

Albert W. Marshall, David William Walkup and Roger Jean-Baptiste Robert Wets,

Order-preserving functions: Applications to majorization and order

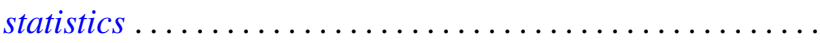

Wellington Ham Ow, An extremal length criterion for the parabolicity of

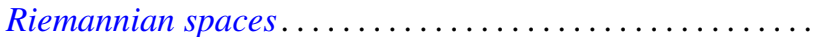

585

Wellington Ham Ow, Criteria for zero capacity of ideal boundary components of

Riemannian spaces...................................... 591

J. H. Reed, Inverse limits of indecomposable continua .................. 597

Joseph Gail Stampfli, Minimal range theorems for operators with thin spectra . . . 601

Roy Westwick, Transformations on tensor spaces..................... 613

Howard Henry Wicke, The regular open continuous images of complete metric

spaces ........................................... 621

Abraham Zaks, A note on semi-primary hereditary rings .............. 627

Thomas William Hungerford, Correction to: "A description of $\operatorname{Mult}_{i}\left(A^{1}, \cdots, A^{n}\right)$

by generators and relations" ............................. 629

Uppuluri V. Ramamohana Rao, Correction to: "On a stronger version of Wallis' formula".............................................. 629

Takesi Isiwata, Correction: "Mappings and spaces" ................... 630

Henry B. Mann, Josephine Mitchell and Lowell Schoenfeld, Correction to:

"Properties of differential forms in $n$ real variables" .... . .

James Calvert, Correction to: "An integral inequality with applications to the

Dirichlet problem"............................. 